\title{
Fibrous hamartoma of infancy: radiologic features and literature review
}

\author{
Yang Ji ${ }^{1}$, Peizhen $\mathrm{Hu}^{2}$, Chuanshan Zhang ${ }^{3}$, Qingguo Yan², Hong Cheng ${ }^{2}$, Ming Han², Zhe Huang ${ }^{4}$, Xia Wang ${ }^{4}$, \\ Heng $\mathrm{Li}^{4}$ and Yuedong $\mathrm{Han}^{4 *}$
}

\begin{abstract}
Background: Fibrous hamartoma of infancy $(\mathrm{FHI})$ is a rare benign lesion most frequently occurring within the first year of life. So far, just over 200 cases have been reported in the English literature, in which the radiologic findings of FHI have not been fully described. Herein, 2 adult cases of FHI receiving treatment in our hospital and the published cases searched on PubMed are reviewed, with the emphasis on the discussion of the spectrum of MR findings and their histologic correlation.

Case presentation: We present two adult cases who aged 47 years and 19 years with slow growing masses beginning from their childhood in the posterior craniocervical area. On CT and MR imaging, the tumours showed as the superficially located lesions with ill-defined margins that involved the subcutaneous layer and its underlying muscles. The size of the lesions were $21.3 \times 16.7 \times 16 \mathrm{~cm}$ in case 1 and $20.2 \times 19.3 \times 13.6 \mathrm{~cm}$ in case 2 . The tumours demonstrated heterogeneous intensities/signals with the adipose tissue presenting as the disperse strands or small focus of fatty intensity/signal. Parallel or whirling appearance, and dilated vessels were delineated in the cases. Contrast enhancement was administered in case 1 and marked enhancement was found.
\end{abstract}

Conclusions: The usually observed manifestation of FHI on CT and/or MR imaging is the strands of adipose/fibrous intensities traversing the lesions, with the characteristic parallel or whirling appearance in some cases. The tumours with ill-defined margins have the tendency to involve the underlying muscles. Some fibroblastic and adipocytic tumours should be ruled out in differential diagnosis.

Keywords: Fibrous hamartoma of infancy, Soft tissue, Radiologic imaging

\section{Background}

Fibrous hamartoma of infancy(FHI) is a rare benign lesion. It was first described by Reye in 1956 and was named as FHI by Enzinger in 1965 [1, 2]. The vast majority of the cases (91\%) occur within the first year of life and about $25 \%$ of them are congenital [2]. The lesions most frequently involve the superficial soft tissues and may occur anywhere in the body, for example, axilla, upper arm, trunk, external genital area, and so on. The lesions' histological appearance of the three different tissues: fibrous trabeculae, mature adipose cells, and immature mesenchymal tissues, is specific for diagnosis of FHI [1-4].

\footnotetext{
* Correspondence: hanyuedong@126.com

${ }^{4}$ Department of Radiology, GaoXin Hospital, Xi'an Jiao Tong University, No.16, South Tuanjie Road, Xi'an, ShaanXi, China

Full list of author information is available at the end of the article
}

Up to now, just over 200 cases of FHI have been reported [2-6]. However, no images of series of the lesions have been sufficiently investigated and published. Although 5 cases of FHI were included in a case series reported by Lee et al. [7], no detailed radiologic demonstrations were described. On MR imaging, there were reports that the tumours of FHI had signal intensity similar to fibromatosis, and there were also reports that the tumours of FHI had signal intensity similar to lipoma [8-10]. Therefore, the relationship between the different MR imaging appearances and their corresponding histologic components of FHI should be further investigated. In addition, no radiologic findings of FHI in adults have been reported as yet. Herein, we described 2 cases of FHI in adults beginning from their childhood. The radiologic manifestations of the 2 cases, especially the MR imaging findings, together with the reported cases in the English literature, were described. 


\section{Case presentation}

Case 1

An adult male, age 47 years (566 months), presented with a 42 years ( 505 months) history of a slow growing mass in the left posterior craniocervical area measuring $21.3 \times 16.7 \times 16 \mathrm{~cm}$ with multiple dilated vessels on its surface. The patient underwent operation at the age of 26 in another institution, but the surgery had to be terminated at the very beginning because of severe bleeding. Radiography showed a huge soft tissue mass with faint punctuate calcifications. On nonenhanced CT scan, the lesion presented as a multi-lobular heterogeneous density mass at the subcutaneous tissue with mixed lowand high attenuations suggestive of adipose and calcifications (Fig. 1a). No boundaries were seen between the mass and the surrounding structures with the latter being markedly displaced. MR imaging reasserted the demonstrations above except for calcifications, and further showed whirling appearance in the lobules and multiple tortuous signal voids suggesting dilated tumour vessels with the largest diameter of $23.2 \mathrm{~mm}$ both on fat-supressed T1WI and T2WI (Fig. 1b,Fig. 1c). In addition, foci of heterogeneous hyperintensity were also demonstrated, suggestive of subacute hemorrhage. The mass was heterogeneously enhanced after the intravenous administration of Gd-DTPA $(0.1 \mathrm{mmol} / \mathrm{kg})$ (Fig. 1d).
The patient underwent subtotal excision of the tumour which was $3100 \mathrm{~g}$ in weight and recovered from surgery. Histopathology disclosed an FHI with rich collagenous tissue, islands of adipose, and nests of immature mesenchyme (Fig. 1e).

\section{Case 2}

An adult female, age 19 years (232 months), presented with a painless, right sided posterolateral craniocervical mass measuring $20.2 \times 19.3 \times 13.6 \mathrm{~cm}$ from her birth as a neonate. She did not undergo any medical treatment until she was referred to our institution. Radiography showed a huge soft tissue mass with faint punctuate calcifications. The underlying structures were compressed obviously (Fig. 2a). Nonenhanced CT scan demonstrated a multi-lobular ill-circumscribed heterogeneous density mass locating at the subcutaneous layer with mixed low and high attenuations indicative of adipose and calcifications (Fig. 2b). MR imaging confirmed the demonstrations above except for calcifications, and further delineated whirling appearance in the lobules and focal tortuous signal voids suggesting dilated tumour vessels (Fig. 2c,Fig. 2d). The patient underwent complete resection of the tumour which was $2750 \mathrm{~g}$ in weight and fully recovered from surgery. The histologic examination was indicative of FHI with rich collagenous tissue, interspersed adipose, and scattered immature mesenchymal cells (Fig. 2e).
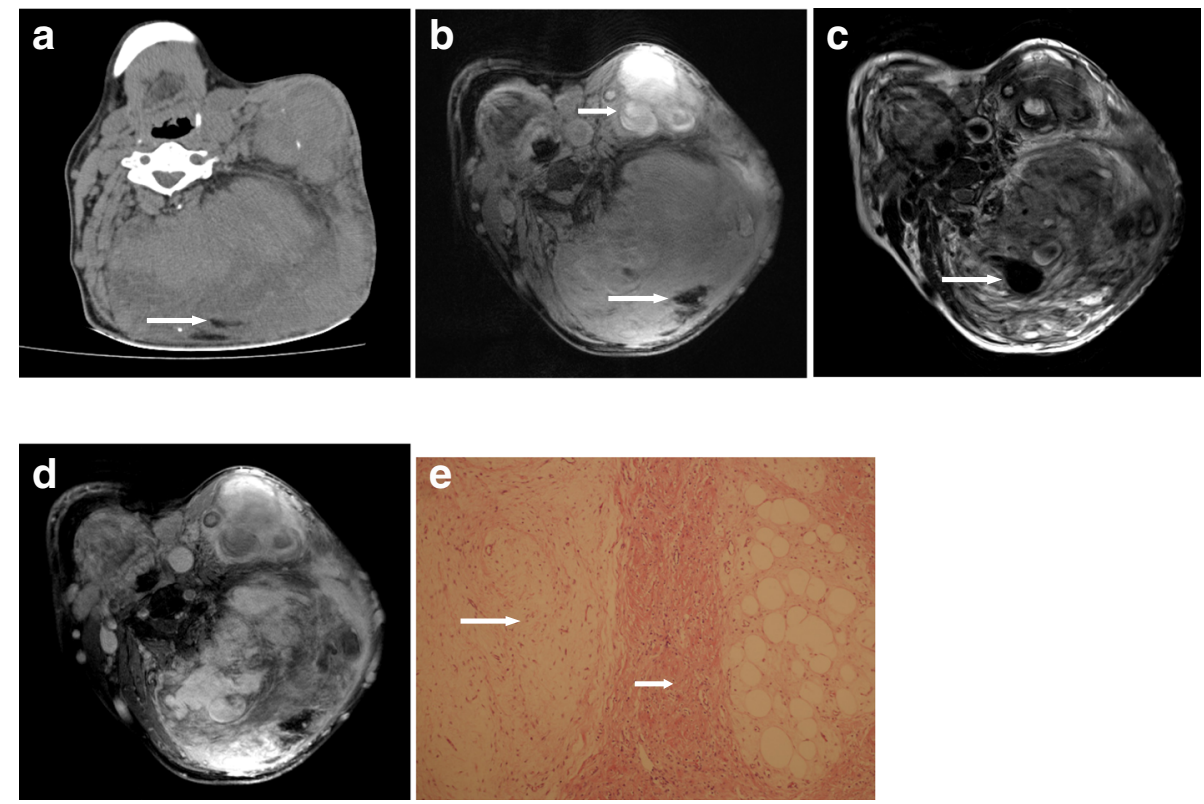

Fig. 1 a Noncontrast CT scan shows stripes of adipose in the mass (arrow) with speckled calcifications. $\mathbf{b}$ Axial fat suppressed $T_{1}$-weighted MR image delineates hypointensity of adipose (arrow) and hyperintensity of multifocal subacute hemorrhages (short arrow). c Axial $T_{2}$-weighted MR image shows the whirling appearance in the lobules combined with the signal void of vessels (arrow). $\mathbf{d}$ Contrast-enhanced axial fat suppressed $\mathrm{T}_{1}$-weighted MR image demonstrates heterogeneous enhancement of the mass. e Photomicrograph of pathologic specimen shows an admixture of mature adipose tissue, nodular aggregate of immature mesenchyme(arrow), and dense bundle of fibrocollagenous tissue (short arrow) (H\&E, $\times 200)$ 

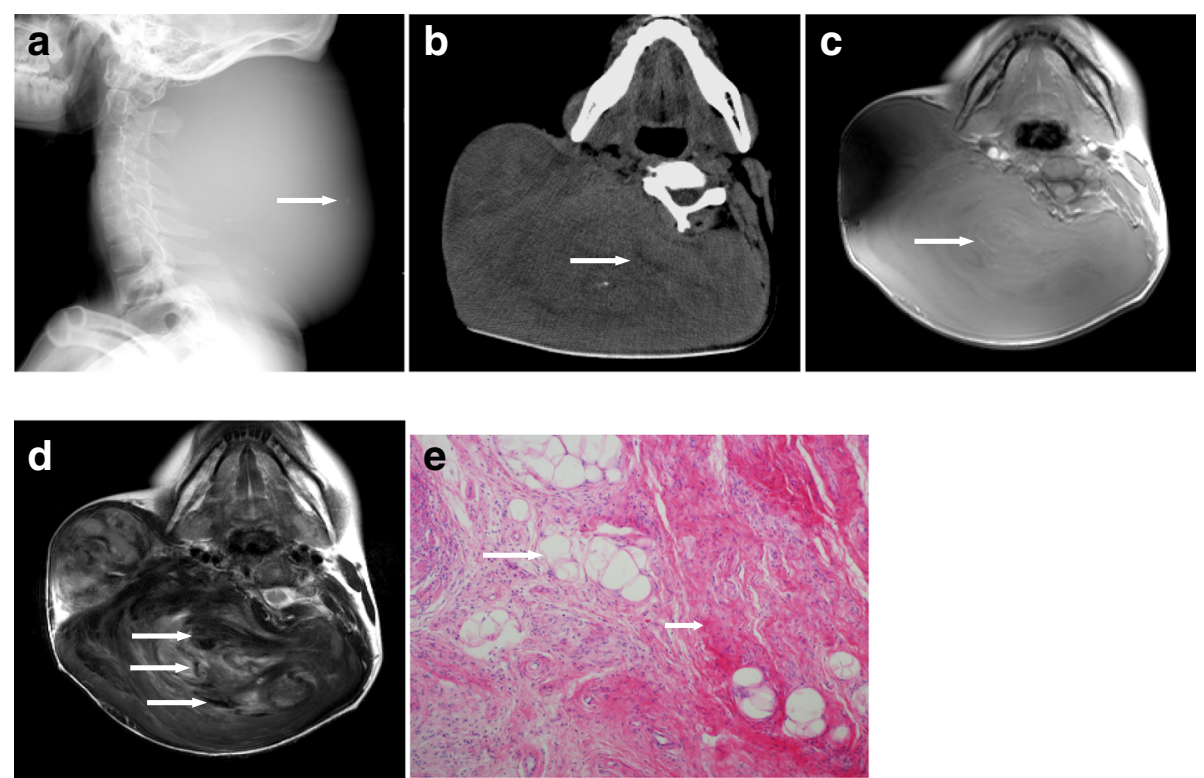

Fig. 2 a Lateral radiograph of the craniocervical area shows a giant soft-tissue mass with faint punctuate calcifications (arrow) and obvious compression of the skull. $\mathbf{b}$ Noncontrast CT scan shows low intensity of adipose (arrow) and high intensity of mineralization in the lobular mass. $\mathbf{c}$ Axial $T_{1}$-weighted MR image demonstrates fine strands of high signal adipose (arrow). $\mathbf{d}$ Axial $T_{2}$-weighted MR image delineates the whirling appearance in the lobules and multiple serpiginous signal voids (arrows). e Photomicrograph of pathologic specimen shows an admixture of islands of mature adipose tissue(arrow), scattered immature mesenchymal cells, and dense bundles of fibrous tissue (short arrow) (H\&E, $\times 200)$

\section{Discussion}

FHI is a distinctly rare lesion occasionally reported in the English literature [1-4]. Only over 200 cases were reported $[2,4,6,11]$ in literature reviews of FHI with enough clinical and pathologic delineations. FHIs are almost all benign masses with the exception of 2 cases in which sarcoma occurred [11]. Although FHIs may present at any time from birth to middle age, they almost always occur in the first two years of life with boys more frequently involved than girls $(2.4: 1)$ [2-5]. Ordinarily, the tumours present as a solitary nontender mass in the subcutaneous soft tissue with the most common locations being axillary regions, trunk, upper arms, chest wall, neck, and external genital areas [1-4]. However, some infrequent symptoms also have been reported, including multiple separate synchronous lesions, hypertrichosis, hyperhidrosis, tuberous sclerosis, Williams syndrome, and so on [4, 11-18]. These less common symptoms seem to represent chance occurrences, rather than true syndrome association $[4,6,11]$.

Because of the rarity of FHI, the radiologic findings of FHI have not been sufficiently investigated in the literature. On PubMed search, we found FHI-related 132 papers in which only 14 cases have detailed clinical and radiologic findings to allow an in-depth imaging analysis (Table 1) [8-10, 12-22]. Of the 16 cases of FHI, including our 2 cases, there were 9 cases undergoing X-ray imaging. X-ray imaging has little value for diagnosis of FHI because FHI lesions only demonstrate as soft tissue masses without characteristics [12, 18, 23, 24]. However, cross-sectional imaging techniques play an important role in the distinction of the lesions from the surrounding structures, and even in the determination of their histological origins. On CT and MR imaging, FHI usually presents as a soft tissue mass with the shape being oval, round flat cake, or irregular with shallow lobules $[5,10$, 12, 18-21, 23-25]. According to the proportion of the different intensities similar to that of fatty tissue or muscle on CT or MR imaging, the authors classified the lesions as the balanced type or non-balanced type. In the balanced type, the proportion of the two components was basically equal $[12-15,19-22]$. In the non-balanced type, however, it was not equal at all, with one of them being predominant and the other one subordinate $[5,8-10$, $16-18,23,26]$. In the first case reported by Loyer et al. who described the MR findings of FHI in 1992 [12], the lesion presented as a mass with proximate proportion of strands similar to the signal intensities of adipose or fibrous tissue. In some other cases reported in the literature, however, the lesions could also be showed as predominant intensity of fibrous tissue traversed by disperse strands of fatty component or vice versa $[8-10,16-18]$. The interspersed strands usually existed in a parallel fashion, or even in a whirling appearance as in our cases [10, 12-15, 18, 24]. For some cases, the adipose or the fibrous tissue might aggregate at the local area in the lesion [19-22].

Of the 16 cases, 8 belonged to the balanced type, 8 to the non-balanced type. 7 cases were found being mainly 


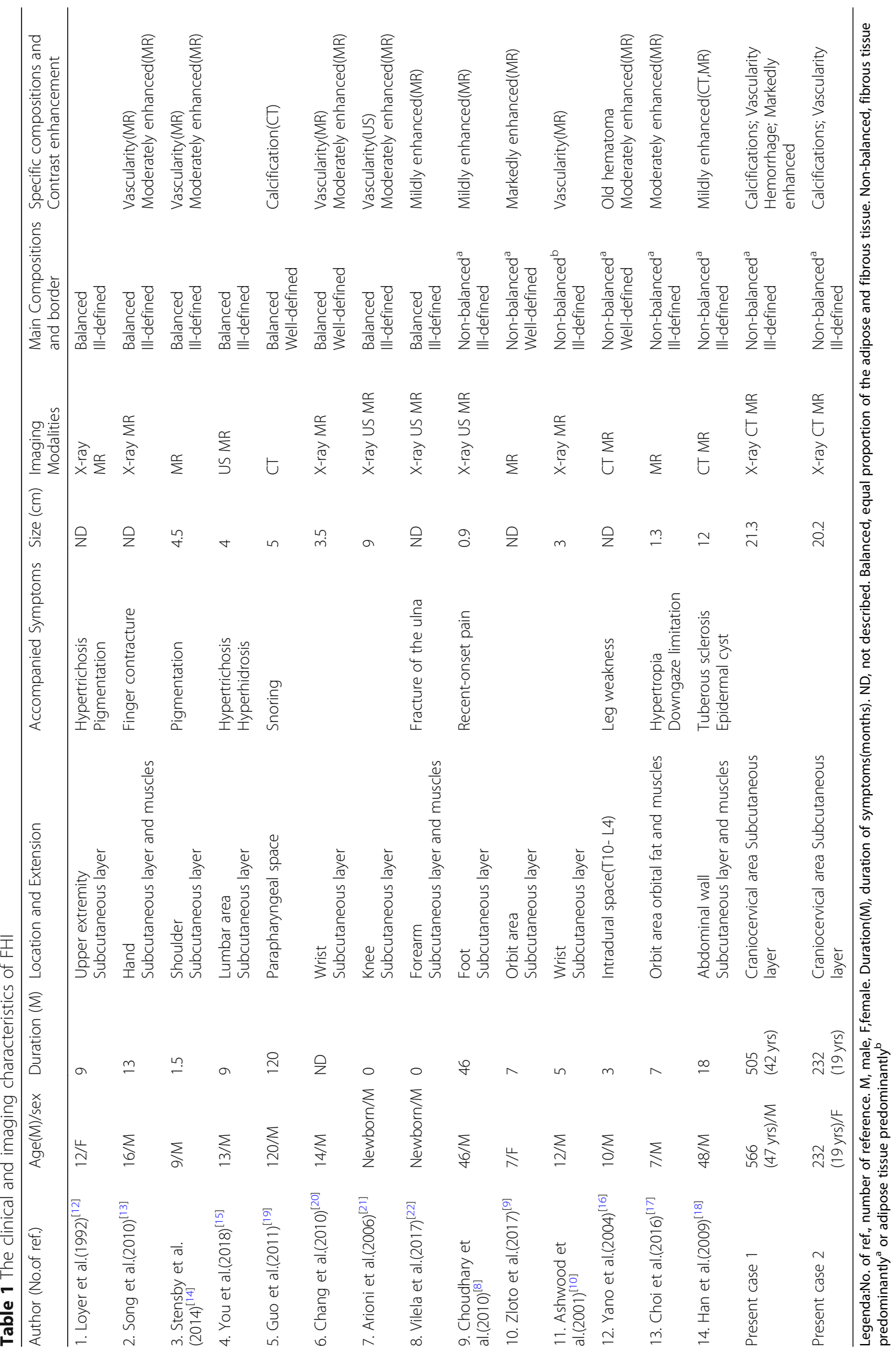


composed of fibrous tissue in the non-balanced type. Relationships among the different types, the margins, and extension of the lesions were observed. There seem to be no relationships between the types of FHI and the margins of the masses, or the types and lesions' extension. The lesions with the ill- or well-defined margins and the lesions limited to the subcutaneous layer or even extended to its underlying muscles all could be found in the cases of two types. However, of the superficially located 14 cases, two masses with the well-defined margins limited to the location of the subcutaneous layer, and twelve masses with the ill-defined margins involved not only the subcutaneous layer $(n=8)$ but also its underlying muscles $(n=4)$. Therefore, the ill-defined masses might have the potential tendency of traversing the deep fascia.

Among the different locations of FHI throughout human bodies, only $7.5 \%$ were in the craniocervical area as in our cases [4]. To our knowledge, this is the first report which delineates the radiologic findings of $\mathrm{FHI}$ in adults. Obviously, our cases should be in the group of non-balanced type. However, some radiologic findings of our lesions are different from most of those reported in the literature. Firstly, the lesions in our cases are larger than the lesions in the reported cases which typically are 1 to $8 \mathrm{~cm}$ in diameter and seldom up to $10 \mathrm{~cm}[2-4,6$, $12,23,25,27]$. Secondly, vascular structures could be found in the lesions in the reported cases on MR imaging [10], in our cases, however, there were more marked vascular structures that had never been seen. Thirdly, calcification was rarely found in FHI, but in our cases calcification occurred. The reason for these appearances might be the extended duration of tumor's growth from childhood to adulthood [4, 12, 24]. For example, we could not find the chondroid component and thrombosis microscopically which usually lead to the formation of calcification, so we believe that this might be the result of long-term degenerative change. In addition, the whirling appearance in the lobules, which is relatively characteristic just as the appearance of parallel fashion, was delineated on MR imaging in our cases, especially on $\mathrm{T}_{2}$-weighted images [10, 12-15, 18, 24].

The differential diagnosis should be performed for distinguishing FHI from other fibroblastic/myofibroblastic and adipocytic tumours. The latter can usually be identified by the means of age at which disease occurs, involved sites, and radiologic findings. For differentiation of FHI with rich fibrous component, fat-equivalent signal across the low signal caused by collagenous component on MRI allows us to exclude tumours such as infantile fibromatosis, myofibromatosis and congenital fibrosarcomas [24-26, 28-30]. However, it might be occasionally difficult for differentiation of FHI with rich adipose tissue from the adipocytic tumours. Lipoma is a common benign tumour in which the adipose tissue is most commonly the predominant component $[2,4,10]$. However, the signals of fibrous strands and dilated vessels that do not exist in lipoma may serve as an indication for correct diagnosis [10]. Lipofibromatosis is a fibro-fatty rare benign tumor of infancy and childhood which typically involves the superficial soft tissues of the distal extremities [31-34]. On MR imaging, the tumour also demonstrates adipose signal intensity interspersed by strands of fibrous low signal intensity [31-34]. In lipoblastomas that are predominantly composed of mature fat also appears heterogeneous signal intensity much like FHI on MR imaging. Unlike FHI, lipofibromatosis and lipoblastoma with parallel and whirling appearance have not been reported [31-34].

\section{Conclusion}

In conclusion, the radiologic appearance of our 2 cases and the reported 14 cases, especially for MR imaging can sufficiently reveal the histologic features of FHI. On MR imaging, FHI could be classified as the balanced or non-balanced type in which the presence of parallel or whirling appearance might be characteristic and can be helpful in differentiating it from the other superficial masses. The tumours' margins could be well- or ill-defined, with the latter having the tendency of involving the underlying muscles. For adults with long history of FHI, the huge volume, calcification, and the increased vascularity might be the additional radiologic characteristics compared with infants. However, the small number of the cases listed in the report limits further disscusion of the radiologic findings of FHI, so more experience should be gotten in the future.

\section{Abbreviations}

CT: Computed tomography; F: Female; FHI: Fibrous hamartoma of infancy; Gd-DTPA: Gadolinium- Diethylenetriaminepentaacetic acid; H\&E: Hematoxylin and eosin stain; M: Male; MR: Magnetic resonance; ND: Not described; No. of ref.: Number of reference

\section{Acknowledgements \\ The authors would like to thank Dr. Xuewen Feng for improving the English language of this article.}

\section{Authors' contributions \\ YJ, YDH and CSZ conceived and designed the study. YJ, YDH, ZH, XW and $\mathrm{HL}$ obtained funding for the study. $Y J$ was a major contributor in writing the manuscript. CSZ, PZH, QGY, HC,and MH performed and interpreted the histological examination of the masses. $\mathrm{ZH}, \mathrm{XW}$ and $\mathrm{HL}$ were involved in study implementation and data collection. YDH made a critical revision of the article. All the authors have read and approved the final manuscript.}

\section{Funding}

No financial support was received.

Availability of data and materials

The datasets used and/or analyzed during the current study are available from the corresponding author on reasonable request. 


\section{Ethics approval and consent to participate}

This report was approved by the Ethics Committee, Gaoxin Hospital, Xi'an Jiao Tong University (Xi'an, China), and the Ethics Committee, First Affiliated Hospital, Xi'an Medical University (Xi'an, China).

\section{Consent for publication}

Written informed consents were obtained from all 2 patients for publication of this report and accompanying images. A copy of the written consent is available for review upon requests.

\section{Competing interests}

The authors declare that they have no competing interests.

\section{Author details}

'Department of Imaging Center, First Affiliated Hospital, Xi'an Medical University, Xi'an, ShaanXi, China. 'Department of Pathology, First affiliated Hospital of Air Force Medical University, Xi'an, ShaanXi, China. ${ }^{3}$ Department of Pathology, Third Central Hospital, Tianjin, China. ${ }^{4}$ Department of Radiology, GaoXin Hospital, Xi'an Jiao Tong University, No.16, South Tuanjie Road, Xi'an, ShaanXi, China.

Received: 15 March 2019 Accepted: 26 July 2019

Published online: 03 August 2019

\section{References}

1. Reye RD. A consideration of certain subdermal fibromatous tumors of infancy. J Pathol Bacteriol. 1956;72(1):149-54

2. Enzinger FM. Fibrous hamartoma of infancy. Cancer. 1965;18(2):241-8.

3. Sotelo-Avila C, Bale PM. Subdermal fibrous hamartoma of infancy: pathology of 40 cases and differential diagnosis. Pediatr Pathol. 1994;14(1): 39-52.

4. Dickey GE, Sotero-Avila C. Fibrous hamartoma of infancy: current review. Pediatr Dev Pathol. 1999;2(3):236-43.

5. Eyer de Jesus L, Schott GV, Jurema NR, Bilche GG, Penha M. Children's fibrous hamartoma: extensive injury involving brachial plexus. Acta Ortop Bras. 2006:14(4):229-30.

6. Saab ST, McClain CM, Coffin CM. Fibrous hamartoma of infancy: a clinicopathologic analysis of 60 cases. Am J Surg Pathol. 2014;38(3):394-401.

7. Lee S, Choi YH, Cheon JE, Kim MJ, Lee MJ, Koh MJ. Ultrasonographic features of fibrous hamartoma of infancy. Skelet Radiol. 2014;43(5):649-53.

8. Choudhary AK, Adapa P. Precalcaneal congenital soft-tissue lesions in children: a case report of fibrous hamartoma of infancy and an approach to differential diagnosis. Radiol Case Rep. 2010;5(3):373.

9. Zloto O, Aviel-Ronen S, Rosner M. An unusual location of fibrous hamartoma of infancy in the eyelid. Ocul Oncol Pathol. 2017:3(1):8-10.

10. Ashwood N, Witt JD, Hall-Craggs MA. Fibrous hamartoma of infancy at the wrist and the use of MRI in preoperative planning. Pediatr Radiol. 2001;31(6): 450-2.

11. Al-Ibraheemi A, Martinez A, Weiss SW, Kozakewich HP, Perez-Atayde AR, Tran H, Parham DM, Sukov WR, Fritchie KJ, Folpe AL. Fibrous hamartoma of infancy: a clinicopathologic study of 145 cases, including 2 with sarcomatous features. Mod Pathol. 2017;30(4):474-85.

12. Loyer EM, Shabb NS, Mahon TG, Eftekhari F. Fibrous hamartoma of infancy MR-pathologic correlation. J Comput Assist Tomogr. 1992;16(2):311-3.

13. Song YS, Lee IS, Kim HT, Choi KU, Song JW. Fibrous hamartoma of infancy in the hand: unusual location and MR imaging findings. Skelet Radiol. 2010; 39(10):1035-8

14. Stensby JD, Conces MR, Nacey NC. Benign fibrous hamartoma of infancy: a case of MR imaging paralleling histologic findings. Skelet Radiol. 2014; 43(11):1639-43.

15. You MH, Shin DH, Choi JS, Kim BS, Kim Y, Kim JG. The first reported case of fibrous hamartoma of infancy with hyperhidrosis and hypertrichosis in Korea. J Korean Med Sci. 2018;33(9):e66.

16. Yano S, Hida K, Nagashima K, Iwasaki Y. Spinal fibrous hamartoma of infancy: case report. Neurosurg. 2004;55(3):712.

17. Choi SH, Hwang JM, Kim N. Orbital fibrous hamartoma of infancy. J AAPOS. 2016:20(1):68-9.

18. Han HJ, Lim GY, You CY. A large infiltrating fibrous hamartoma of infancy in the abdominal wall with rare associated tuberous sclerosis. Pediatr Radiol. 2009;39(7):743-6.
19. Guo YK, Ning G, Zhao FM, Qu HB. Fibrous hamartoma of infancy mimicking teratoma in the parapharyngeal space on multidetector row CT. Pediatr Radiol. 2011:41(6):785-7.

20. Chang WC, Huang GS, Lee HS, Lee $\mathrm{CH}$. Fibrous hamartoma of infancy at the wrist. Pediatr Int. 2010;52(2):317-8.

21. Arioni C, Bellini C, Oddone M, Risso FM, Scopesi F, Nozza P, Serra G, Tomà P. Congenital fibrous hamartoma of the knee. Pediatr Radiol. 2006;36(5):453-5.

22. Vilela VM, Ribeiro VM, Paiva JC, Pires DD, Santos LS. Clinical and radiological characterization of fibrous hamartoma of infancy. Radiol Bras. 2017:50(3):204-5.

23. Jeong $\mathrm{IH}$, Kim JH, Kim SH. Fibrous hamartoma of infancy(FHI) developed in trunk. J Korean Neurosurg Soc. 2004;36(4):331-3.

24. Eich GF, Hoeffel JC, Tschappefer H, Gassner I, Willi UV. Fibrous tumors of children: imaging features of a heterogenous group of disorders. Pediatr Radiol. 1998;28(7):500-9.

25. Patrick LE, O'Shea P, Simoneaux SF, Gay BB Jr, Atkinson GO. Fibromatoses of childhood: the spectrum of radiographic findings. Am J Roentgenol. 1996; 166(1):163-9.

26. Keskin M, Tosun Z, Toy H, Savaci N. Subdermal fibrous hamartoma of infancy in the hand. Scand J Plast Reconstr Surg Hand Surg. 2007;41(4):211-4.

27. McGowan J 4th, Smith CD, Maize J Jr, Cook J. Giant fibrous hamartoma of infancy: a report of two cases and review of the literature. J Am Acad Dermatol. 2011:64(3):579-86.

28. Coffin CM, Alaggio R. Fibroblastic and myofibroblastic tumors in children and adolescents. Pediatr Dev Pathol. 2012;15(1 Suppl):127-80.

29. Sargar KM, Sheybani EF, Shenoy A, Aranake-Chrisinger J, Khanna G. Pediatric fibroblastic and myofibroblastic tumors: a pictorial review. Radiographics. 2016;36(4):1195-214

30. Laffan EE, Ngan BY, Navarro OM. Pediatric soft-tissue tumors and pseudotumors: MR imaging features with pathologic correlation: part 2. Tumors of fibroblastic/myofibroblastic, so-called fibrohistiocytic, muscular, lymphomatous, neurogenic, hair matrix, and uncertain origin. RadioGraphics. 2009;29(4):e36.

31. Costa Dias S, McHugh K, Sebire NJ, Bulstrode N, Glover M, Michalski A. Lipofibromatosis of the knee in a 19-month-old child. J Pediatr Surg. 2012; 47(5):1028-31.

32. Fetsch JF, Miettinen M, Laskin WB, Michal M, Enzinger FM. A clinicopathologic study of 45 pediatric soft tissue tumors with an admixture of adipose tissue and fibroblastic elements, and a proposal for classification as lipofibromatosis. Am J Surg Pathol. 2000;24(11):1491-500.

33. Sheybani EF, Eutsler EP, Navarro OM. Fat-containing soft-tissue masses in children. Pediatr Radiol. 2016:46(13):1760-73.

34. Navarro OM, Laffan EE, Ngan BY. Pediatric soft-tissue tumors and pseudotumors: MR imaging features with pathologic correlation: part 1. Imaging approach, pseudotumors, vascular lesions, and adipocytic tumors. RadioGraphics. 2009;29(3):887-906.

\section{Publisher's Note}

Springer Nature remains neutral with regard to jurisdictional claims in published maps and institutional affiliations.

Ready to submit your research? Choose BMC and benefit from:

- fast, convenient online submission

- thorough peer review by experienced researchers in your field

- rapid publication on acceptance

- support for research data, including large and complex data types

- gold Open Access which fosters wider collaboration and increased citations

- maximum visibility for your research: over $100 \mathrm{M}$ website views per year

At BMC, research is always in progress.

Learn more biomedcentral.com/submissions 